\title{
2,4,6-Tribromophenol Interferes with the Thyroid Hormone System by Regulating Thyroid Hormones and the Responsible Genes in Mice
}

\author{
Dongoh Lee ${ }^{1}$, Changhwan Ahn ${ }^{1}$, Eui-Ju Hong ${ }^{2}$, Beum-Soo An ${ }^{3}$, Sang-Hwan Hyun ${ }^{4}$, \\ Kyung-Chul Choi ${ }^{5}$ and Eui-Bae Jeung ${ }^{1, *}$ \\ 1 Laboratory of Veterinary Biochemistry and Molecular Biology, College of Veterinary Medicine, \\ Chungbuk National University, Cheongju, Chungbuk 362-763, Korea; eastdaylight@gmail.com (D.L.); \\ prac@naver.com (C.A.) \\ 2 Laboratory of Veterinary Biochemistry, College of Veterinary Medicine, Chungnam National University, \\ Daejeon 305-764, Korea; euijuhong@hotmail.com \\ 3 Laboratory of Biochemistry, Department of Biomaterial Science, College of Natural Resources and Life \\ Science, Pusan National University, Miryang, Kyeongnam 50463, Korea; anbs@pusan.ac.kr \\ 4 Laboratory of Veterinary Biotechnology and Embryology, College of Veterinary Medicine, \\ Chungbuk National University, Cheongju, Chungbuk 362-763, Korea; shhyun@chungbuk.ac.kr \\ 5 Laboratory of Biochemistry and Immunology, College of Veterinary Medicine, \\ Chungbuk National University, Cheongju, Chungbuk 362-763, Korea; kchoi@chungbuk.ac.kr \\ * Correspondence: ebjeung@chungbuk.ac.kr; Tel.: +82-43-261-2397; Fax: +82-43-267-3150
}

Academic Editor: Huixiao Hong

Received: 15 February 2016; Accepted: 7 July 2016; Published: 12 July 2016

\begin{abstract}
Tribromophenol (TBP) is a brominated flame retardant (BFR). Based on its affinity for transthyretin, TBP could compete with endogenous thyroid hormone. In this study, the effects of TBP on the thyroid hormone system were assessed in mice. Briefly, animals were exposed to 40 and $250 \mathrm{mg} / \mathrm{kg}$ TBP. Thyroid hormones were also administered with or without TBP. When mice were treated with TBP, deiodinase 1 (Dio1) and thyroid hormone receptor $\beta$ isoform 2 (Thr $\beta 2$ ) decreased in the pituitary gland. The levels of deiodinase 2 (Dio2) and growth hormone (Gh) mRNA increased in response to $250 \mathrm{mg} / \mathrm{kg}$ of TBP, and the relative mRNA level of thyroid stimulating hormone $\beta$ (Tsh $\beta$ ) increased in the pituitary gland. Dio1 and Thr $\beta 1$ expression in the liver were not altered, while Dio1 decreased in response to co-treatment with thyroid hormones. The thyroid gland activity decreased in response to TBP, as did the levels of free triiodothyronine and free thyroxine in serum. Taken together, these findings indicate that TBP can disrupt thyroid hormone homeostasis and the presence of TBP influenced thyroid actions as regulators of gene expression. These data suggest that TBP interferes with thyroid hormone systems
\end{abstract}

Keywords: endocrine disruptor; 2,4,6-tribromophenol; thyroid hormone

\section{Introduction}

The thyroid hormones, triiodothyronine (T3) and thyroxine (T4), are tyrosin-based hormones produced by the thyroid gland that are primarily responsible for the regulation of metabolism [1]. The secretion of hormones is regulated by thyroid-stimulating hormone (TSH). Like other hormones, thyroid hormones bind to several blood proteins such as albumin, thyroxine-binding globulin, and transthyretin [2]. While thyroid hormone levels and binding affinity to blood protein differ among species, the unbound form of T3 in the blood is believed to be the active form [3]. T3 then binds to thyroid hormone receptor (THR) in target cells to regulate thyroid dependent genes [4]. Expression of THR is tissue dependent, and its activity differs by subtype. There are two major isoforms in mouse, 
THR $\alpha$, which is distributed in many various tissues, and THR $\beta$, which is expressed in the brain and pituitary gland [5]. Endocrine system disruption, especially associated with estrogenic compounds, is well known and reported. In addition, thyroid, adrenal, neuroendocrine, and reproductive systems have also recently been identified as targets for endocrine disruptors. Bisphenol A, a well-known weak estrogen agonist [6,7], was recently shown to influence thyroid-related systems, as well as to hinder thyroperoxidase activity and act as a Thr antagonist [8]. Brominated flame retardants (BFRs) are well known for their ability to interrupt thyroid function because of their structural similarity to thyroid hormones. BFRs have also been reported to interfere with thyroid function by regulating various thyroid hormone mediated proteins, such as sodium iodide symporter, thyroperoxidase, thyroxine-binding globulin, transthyretin, deiodinase and THR. Polybrominated diphenyl ether (PBDE), one of the BFRs, has been continuously researched for its association with THs [9-11].

After target cells uptake thyroid hormones, they deiodinate thyroid hormones, and this process is an important thyroid system pathway. Deiodinase II (Dio2) removes one iodide from the outer ring, mainly activating T3 from T4. Deiodination of the inner ring is performed by Deiodinase III (Dio3), thus making the inactive form of reverse triiodothyronine. Removal of iodine from both the outer and inner ring of thyroid hormones is mediated by deiodinase I (Dio1) [9,10]. Dio1 or Dio2 are thyroid hormone response genes which expression is dependent on tissue-specific expression of receptor subtypes. Hypothalamic-pituitary-thyroid gland (HPT) axis is regulated carefully. When the body needs thyroid hormones, thyrotropin-releasing hormone (TRH) is secreted from the hypothalamus. TRH induces thyroid stimulating hormone (TSH) secretion by affecting thyrotrophic cells in the adenohypophysis. TSH increases production of thyroid hormones in the thyroid gland. Its production is also dependent on iodide uptake in the thyroid gland. Total hormone or free hormone and thyroid stimulating hormone levels are indicators of thyroid status of the body [12]. The levels of these hormones modulate the expression of marker genes. Tissue-specific expression of THR and Dio is regulated by serum thyroid hormone levels. Enzyme activity of Dio1 is highly induced by T3 in rodent liver, while THR is suppressed by thyroid hormones. These negative or positive feedback systems are essential for regulating the blood or tissue thyroid hormone levels. Induction of Dio1 is thought to participate in transforming T4 into rT3 or T3 to 3,3'-diiodothyronine (D2), thus suppressing hormone activity in the tissues. THR decrease in target tissues hinders the hormone entrance to cells [5,12].

BFRs are essential to plastics that are required to endure high temperatures. For example, they are widely used in electrical equipment, polyurethane foams and antifungal agents. Although some harmful BFRs have been banned in a few countries, similar substitutions are being continuously produced, and their potential effects are not currently known. 2,4,6-Tribromophenol (TBP) is a BFR that has been identified as a thyroid hormone disruptor. In the United States, over 23,000 tons of TBP were produced in 2006, while 3600 tons were produced in Japan in 2001 [13,14]. A previous study showed that TBP had a high binding affinity to transthyretin and did not bind to THR in vitro [15]. Chronic exposure of zebrafish to TBP impaired reproduction. TBP was also shown to have adverse effects against estrogen and androgen levels [16]. Following exposure to TBP, several genes were up-regulated in females, while they were down-regulated in males because thyroid hormones have the opposite effect on estrogen response gene expression [17]. However, others have reported that TBP does not regulate estrogen response genes or proliferation $[18,19]$. Although the effects of TBP on estrogen and androgen have been examined, their effects on the thyroid system have not been thoroughly investigated. Therefore, this study was conducted to investigate the effects of TBP on the thyroid system. 


\section{Experimental Section}

\subsection{Chemicals}

T3, T4 and TBP were purchased from Sigma-Aldrich (St. Louis, MO, USA). Stock solutions were made by dissolving chemicals in dimethyl sulfoxide (DMSO; Santa Cruz Biotechnology, Santa Cruz, CA, USA) and diluting them with corn oil (Sigma-Aldrich) when needed.

\subsection{Animals}

Post-natal day (PND) 14 female ICR mice with a dam were purchased from SAMTAKO (Gyeonggi-do, Korea) and allowed to acclimate for 7 days. Each group of five mice $(n=5)$ was breed in a polycarbonate cage with non-phytoestrogen beta chip bedding. To eliminate xenoestrogenic effects other than those exerted by the drugs administered, a non-steroid pellet diet AIN-76A (Central Lab Animal Inc., Seoul, Korea) and sterile water were provided ad libitum. The temperature of the environment was set at $20{ }^{\circ} \mathrm{C}-24{ }^{\circ} \mathrm{C}$ with $40 \%-60 \%$ relative humidity and a 12-h light-dark cycle. A $1000 \mathrm{mg} / \mathrm{kg}$ dose of TBP killed half of the mice in the groups. Therefore, two doses of TBP (40, $250 \mathrm{mg} / \mathrm{kg}$ ) were administered at PND 21 days. TBP is generally used as a flame retardant, so exposure to TBP via the GI tract is much rarer than other forms of exposure. Therefore, to avoid first pass effect, we used subcutaneous injection rather than oral administration for 20 days. T3 $(100 \mu \mathrm{g} / \mathrm{kg})$ and T4 $(100 \mu \mathrm{g} / \mathrm{kg})$ were also administered or not TBP $(250 \mathrm{mg} / \mathrm{kg})$ to evaluate the interference effect of TBP with thyroid hormone. The dose of TBP were determined due to IUCLID dataset, and extrapolate by extrapolation equation [20]. The animals were sacrificed 1 day after the last administration. The Institutional Animal Care and Use Committee (IACUC) of Chungbuk National University approved all animal experimental procedures (Approval No. CBNUA-866-15-01).

\subsection{Quantitative Real-Time $q P C R$}

Mice were sacrificed by cervical dislocation. Organs were washed with cold sterile saline and homogenized in TRIzol (Life Technologies, Carlsbad, CA, USA) with a bullet blender (Next Advance, Averill Park, NY, USA). Total RNA was extracted from the homogenate according to the manufacturer's instructions. The integrity of total RNA was confirmed by the $28 \mathrm{~S} / 18 \mathrm{~S}$ and $5 \mathrm{~S}$ rRNA integrity with electrophoresis. Total RNA concentration was measured, and $1 \mu \mathrm{g}$ of RNA was reverse transcribed using Moloney murine leukemia virus (mMLV) reverse transcriptase (iNtRON Bio, Gyeonggi-do, Korea) with a random 9-mer primer (TaKaRa Bio Inc., Shiga, Japan) to produce first-strand complementary DNA (cDNA). $1 \mu \mathrm{L}$ of cDNA template was added to $10 \mu \mathrm{L}$ of $2 x S Y B R$ Premix Ex Taq (TaKaRa Bio Inc.) and 10 pmol of each specific primer. qPCR was performed under the following conditions: 40 cycles of denaturation at $95^{\circ} \mathrm{C}$ for $30 \mathrm{~s}$, annealing at $60^{\circ} \mathrm{C}$ for $30 \mathrm{~s}$, and extension at $72{ }^{\circ} \mathrm{C}$ for $30 \mathrm{~s}$. The threshold cycle (CT) value was determined automatically during the exponential phase of the delta CT fluorescence detection graph. 18S RNA (18S) was used as an endogenous reference, while deiodinase 1 (Dio1), deiodinase 2 (Dio2), thyroid hormone receptor $\beta$ isoform 2 (Thr $\beta 2$ ), thyroid hormone receptor $\beta$ isoform 1 (Thr $\beta 1$ ), thyroid stimulating hormone $\beta$ $(T s h \beta)$ and growth hormone (Gh) were the genes of interest (GOI). Relative quantification was based on the comparison of $\mathrm{CT}$ at a constant fluorescent intensity. The amount of transcript is inversely related to the observed CT, and for every twofold dilution in the transcript, CT is expected to increase by 1 . Relative expression was calculated using the equation $R=2^{-(\Delta C \text { Tsample }-\Delta C \text { Tcontrol })}$.

\subsection{Histology}

Thyroid gland was dissected along with the trachea and fixed with $4 \%$ neutral buffered formalin for 1 day. Tissue processing was performed using a Tissue-Tek VIP 5 system (Sakura, Torrance, CA, USA) according to the manufacturer's instructions. Paraffin block and tissue slides were generated using a LEICA (Wetzlar, Germany) EG1150H and LEICA RM2255, respectively. Slides contained two thyroid glands, and each slide was sectioned at $4 \mu \mathrm{m}$. Hematoxylin \& eosin staining was 
conducted according to the general protocols, after which samples were mounted with mounting medium (Sigma-Aldrich). To evaluate the activity of the thyroid gland, the surface area of the thyroid follicle and epithelium was measured using the ImageJ software with five slides for each group. The volume densities of thyroid follicles, follicular epithelium, colloid, interfollicular tissue and capillary network were measured, and calculated activation index of the thyroid gland. The activation index, which represents the ratio of the volume density of follicular epithelium to the volume density of colloid was introduced by Kalisnik [21]. All histological and stereological analyses were made by the same researcher.

\subsection{Serum Hormone Analysis}

Blood was collected from the abdominal vena cava and clotted at room temperature for $1 \mathrm{~h}$. Clotted blood was centrifuged at $2000 \mathrm{~g}$ for $15 \mathrm{~min}$ at $4{ }^{\circ} \mathrm{C}$. Next, the supernatant was carefully drained and stored at $-80^{\circ} \mathrm{C}$ until analysis. The serum levels of free T3 and T4 were measured using LKF31 and LFT42 kits, (Siemens, Berlin, Germany). This hormone assay is a direct or single test assay, and its results are interpolated from a stored standard curve calibrated in terms of free T3/T4 concentrations. All procedures for this assay were processed according to the manufacturer's instructions. The value of hormones was analyzed by an Immulite 1000 small bench top immunoassay analyzer (Siemens).

\subsection{Statistical Analysis}

Bar graphs are presented as the means \pm standard deviation (SD) and box and whisker graph are presented with the median, mean, 1.5 interquartile range and outliers. Experimental results were analyzed by one-way ANOVA and Tukey's studentized range test. Statistical analyses were performed using SAS (version 9.2; SAS Institute, Cary, NC, USA). $p$ values $<0.05$ were considered significant.

\section{Results}

\subsection{The mRNA Expression of Thyroid Hormone-Related Genes in the Pituitary Gland}

To investigate the effects of TBP in the mouse pituitary gland, we observed several genes related to thyroid hormones. Mice were exposed to TBP with or without thyroid hormones to investigate the competitive effects of TBP with blood transthyretin.

The levels of a down-regulated indicator of thyroid hormones, Dio1, in the pituitary gland decreased by over $80 \%$ in response to both 40 and $250 \mathrm{mg} / \mathrm{kg}$ of TBP. In the presence of the extra thyroid hormones, T3 and T4, the repressive effects of TBP were further accentuated (Figure 1A). In contrast to Dio1 expression, Dio2 increased in the TBP treated groups (40 and $250 \mathrm{mg} / \mathrm{kg}$ ). As expected, Dio2 mRNA decreased significantly in response to treatment with T4 (0.47-fold compared to Ve group) alone, but this decrease was reversed when the samples were also treated with TBP. The mRNA levels of Dio 2 were not significantly changed in the T3-treated group with and without TBP (Figure 1B). In the growth stage, thyroid hormones stimulate the secretion of $G h$ in the pituitary gland. We observed robust (4-fold and 7-fold) increases of Gh mRNA levels in response to $40 \mathrm{mg} / \mathrm{kg}$ TBP and $250 \mathrm{mg} / \mathrm{kg}$ TBP, respectively, compared to the control group. The expression of $G h$ mRNA was also induced by $\mathrm{T} 3$ and T4, with a greater response being observed in T3 (Figure 1C). While T3-induced Gh mRNA was not affected by co-treatment with TBP, robust increases (10-fold) were observed in response to combined treatment with TBP and T4 (Figure 1C). As shown in Figure 1D, Tsh $\beta$ mRNA expression was reduced in the T3 or T4 treated group, suggesting negative feedback on TSH. The co-treatment effects of TBP with T3 and T4 were not comparable (Figure 1D). In parallel with Dio1, Thr $\beta 2$ mRNA was decreased by over $60 \%$ in response to both 40 and $250 \mathrm{mg} / \mathrm{kg}$ TBP. However, the effects of T3 and $\mathrm{T} 4$ on $T h r \beta 2$ were not significant (Figure 1E). 


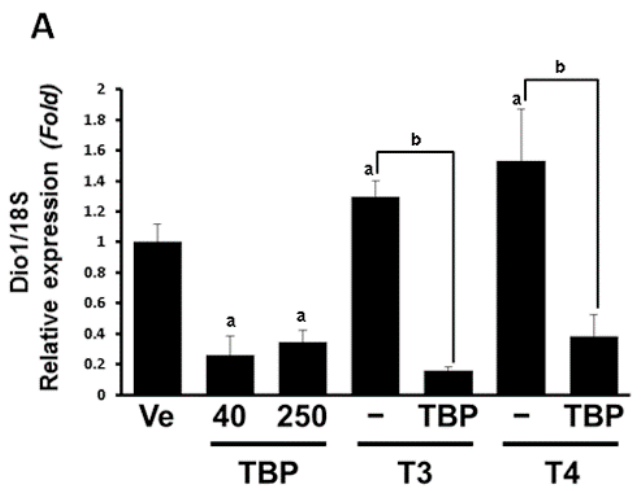

B

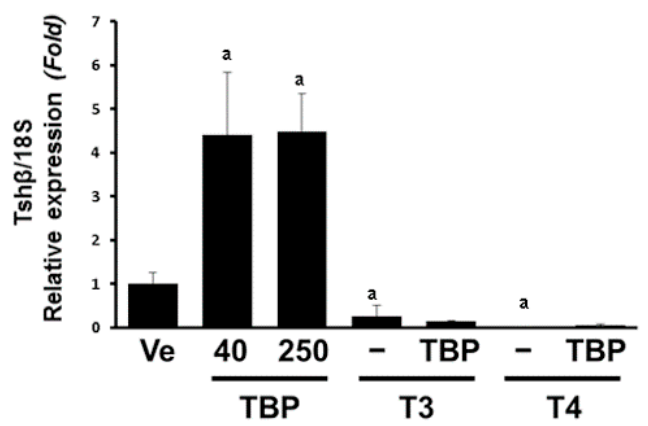

C
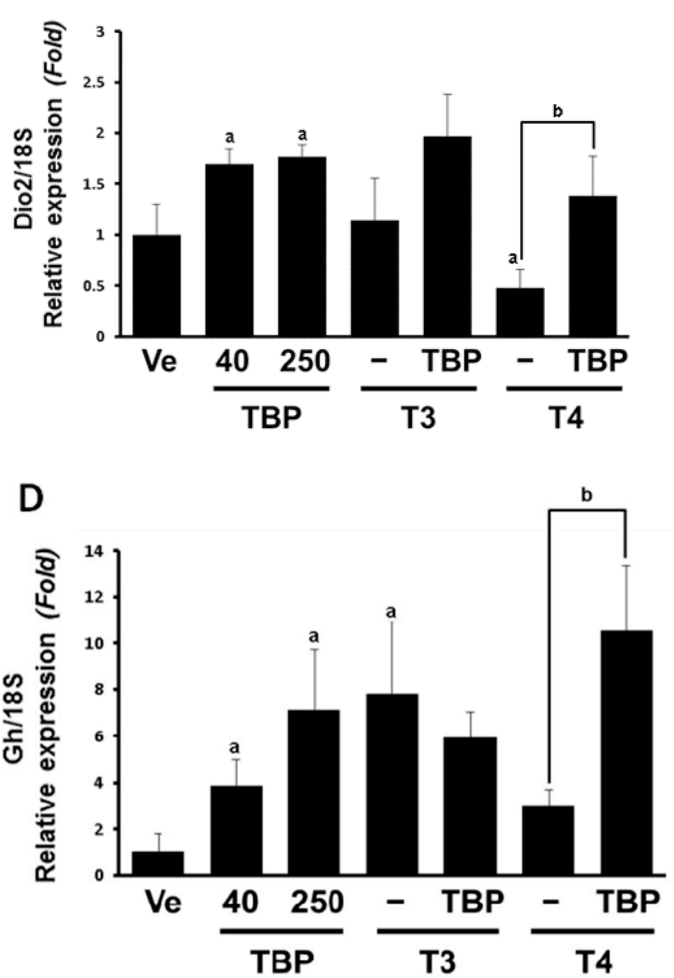

Figure 1. Cont. 


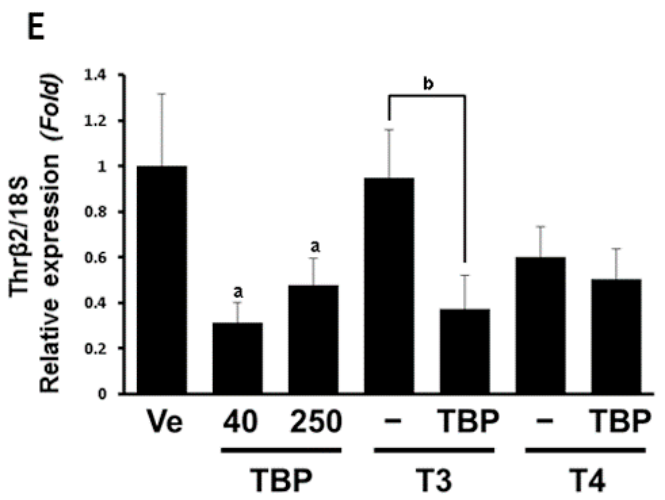

Figure 1. Expression levels of Dio1 (A); Dio2 (B); Gh (C); Tsh $\beta$ (D) and Thr $\beta 2$ (E) mRNA in the pituitary gland. Results presented in the bar graph are divided according to chemical administered and subdivided according to the presence or absence of 2,4,6-tribromophenol. Ve, vehicle; T3, triiodothyronine; T4, thyroxine; TBP, 2,4,6-tribromophenol. ${ }^{\mathrm{a}} p<0.05$ versus vehicle, ${ }^{\mathrm{b}} p<0.05$ versus without TBP. Data are presented as the mean \pm SD.

\subsection{The mRNA Expression of Dio1 and Thr $\beta 1$ in the Liver}

To assess the effects of TBP in other tissues, we monitored thyroid hormone-related genes in the liver, which is responsible for most enzymatic regulation of hormones, as well as production and secretion of some thyroid hormone binding proteins. TBP alone did not significantly change the Dio1 mRNA levels. However, both T3 (14-fold) and T4 (18-fold) highly upregulated Dio1 expression, while this induction was significantly repressed when TBP was coadministered (Figure 2A). As a major subtype of thyroid hormone receptor in the liver, Thr $\beta 1$ expression was tested. Thr $\beta 1$ transcripts were not affected by TBP in the absence or presence of T3 and T4. However, Thr $\beta 1 \mathrm{mRNA}$ was suppressed in the T3 (0.39-fold) and T4 (0.39-fold) treated group (Figure 2B).
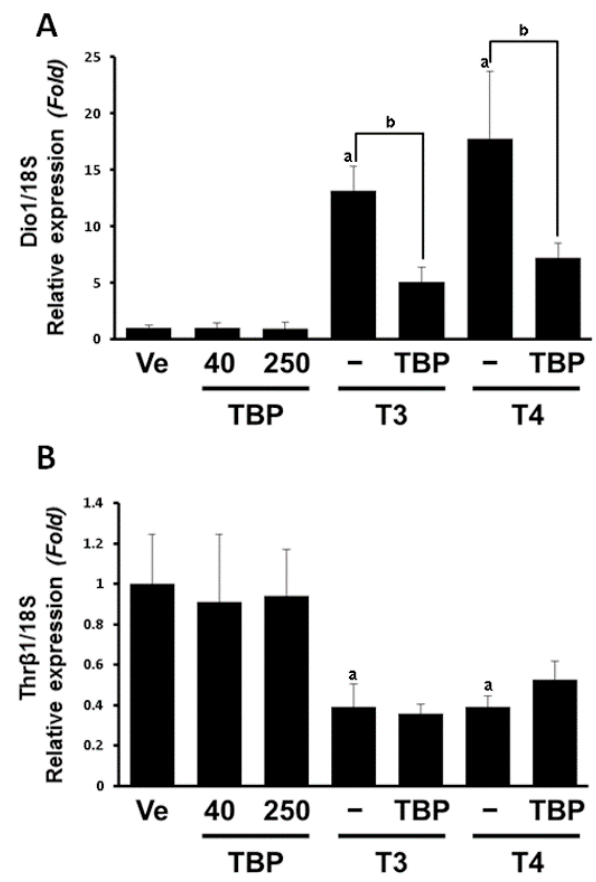

Figure 2. Expression levels of Dio1 (A) and Thr $\beta 1$ (B) mRNA in liver. Results presented in the bar graph are divided according to chemical administered and subdivided according to the presence or absence of 2,4,6-tribromophenol. Ve, vehicle; T3, triiodothyronine; T4, thyroxine; TBP, 2,4,6-tribromophenol. a $p<0.05$ versus vehicle, ${ }^{\mathrm{b}} p<0.05$ versus without TBP. Data are presented as the mean $\pm \mathrm{SD}$. 


\subsection{Morphological and Histological Analysis of Thyroid Gland}

To assess the morphological and histological change by TBP, five slides/group were analyzed. Observation of the follicle shape, follicular epithelium, mesenchyme and adjunct blood vessels did not reveal great changes in the morphology of the thyroid gland (Figure 3). However, indicators of thyroid gland activity (size and number of resorption lacunae, carrying thyroglobulin) were decreased in T3 and T4 treated groups, although they varied in the TBP treated groups (Figure 3A-G).
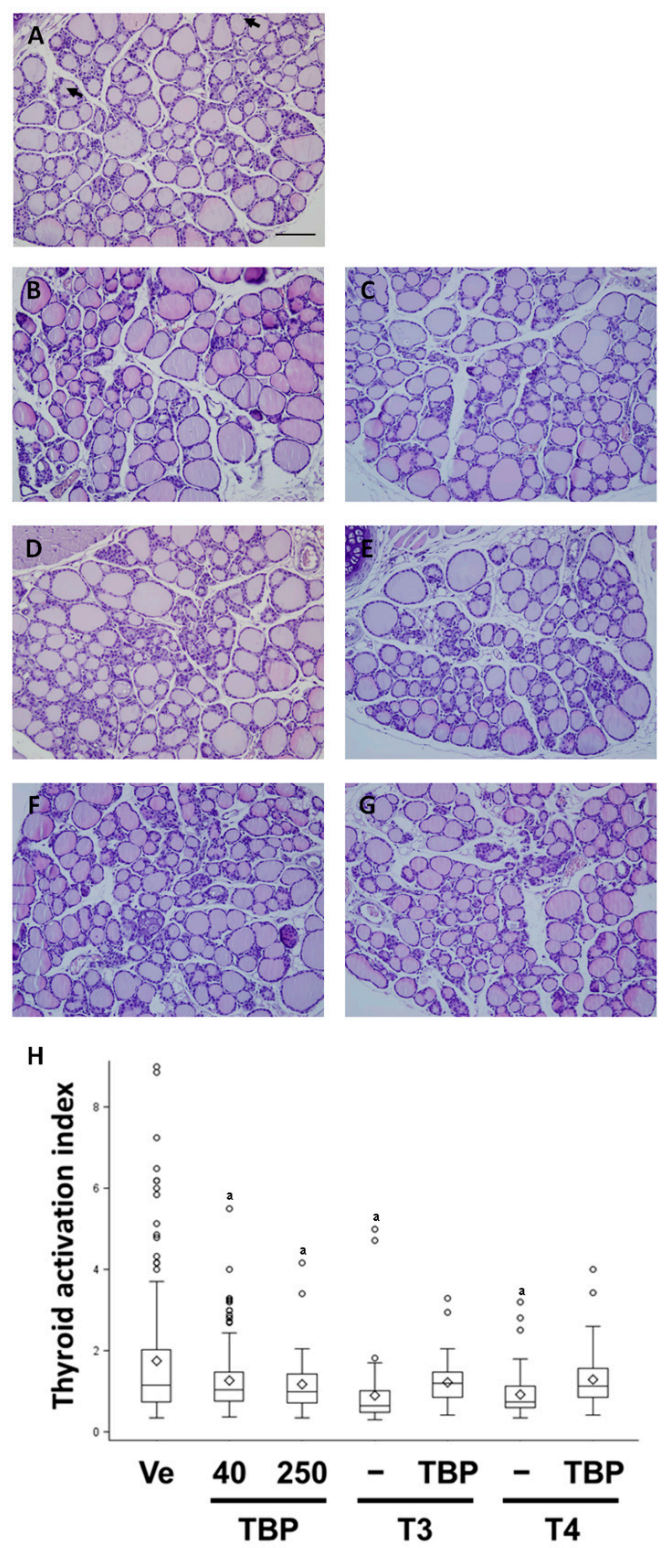

Figure 3. Thyroid gland histology ((A) Ve; (B) TBP 40; (C) TBP 250; (D) T3; (E) TBP-T3; (F) T4; (G) TBP-T4) and thyroid gland activation index (H). Arrow indicates resorption lacunae of follicle. Each thyroid gland was pictured at $200 \times$ magnification. Scale bar represents $100 \mu \mathrm{m}$. Results presented in the box and whisker graph are divided according to chemical administered and subdivided according to the presence or absence of 2,4,6-tribromophenol. Ve, vehicle; T3, triiodothyronine; T4, thyroxine; TBP, 2,4,6-tribromophenol. ${ }^{\mathrm{a}} p<0.05$ versus vehicle, ${ }^{\mathrm{b}} p<0.05$ versus without TBP. Data are presented as the 1.5 interquartile range, mean (diamond) and outlier (circle).

The morphology of the thyroid gland changed when the function was altered by various factors. These morphologies, including follicular volume or epithelial shape, are major indicators of thyroid 
gland function. Adjunct connective tissue and blood vessels are also important indicators of thyroid gland function. During production of thyroglobulin, follicles of active thyroid glands are much larger than those of normal or inactive glands. In this study, the thyroid activation index calculated from follicle size varied among groups. Thus, data were presented as box and whisker plots. Partially large follicles and reduced epithelia were observed in the thyroid hormone and TBP group and the co-treatment group. Thus, the overall thyroid activation index was reduced in the thyroid hormone (T3 for 0.78-fold, T4 for 0.40 -fold) and TBP ( $40 \mathrm{mg} / \mathrm{kg}$ for 0.62 -fold, $250 \mathrm{mg} / \mathrm{kg}$ for 0.78 -fold)group, as well as the co-treatment group when compared with the vehicle control group (Figure $3 \mathrm{H}$ ).

\subsection{Concentration of Free T3 (fT3) and T4 (fT4) Levels in Serum}

The levels of T3 and T4 were assessed in mouse sera after exposure to endogenous thyroid hormones or exogenous TBP compound. Due to the limited volume acquired from mouse serum, only free T3 and T4 were analyzed in this study. The fT3 and fT4 levels were decreased in a dose-dependent manner in response to TBP exposure, whereas fT3 was not detected in T3 treated mice (Table 1). Interestingly, when mice were treated with T3, fT4 was significantly increased, while TBP repressed the increase. T4 with or without TBP had a similar effect as T3 on the level of fT4. T4 alone did not significantly alter fT3 concentrations, although TBP reduced fT3 when combined with T3.

Table 1. Free triiodothyronine and free thyroxine levels in serum.

\begin{tabular}{|c|c|c|c|c|c|c|c|}
\hline \multirow{2}{*}{ Hormones } & \multirow{2}{*}{$\begin{array}{c}\mathrm{Ve} \\
-\end{array}$} & \multicolumn{2}{|c|}{ TBP (mg/kg) } & \multicolumn{2}{|c|}{ T3 $(100 \mu \mathrm{g} / \mathrm{kg})$} & \multicolumn{2}{|c|}{$\mathrm{T} 4(100 \mu \mathrm{g} / \mathrm{kg})$} \\
\hline & & 40 & 250 & - & TBP $(250 \mathrm{mg} / \mathrm{kg})$ & - & TBP $(250 \mathrm{mg} / \mathrm{kg})$ \\
\hline $\begin{array}{c}\text { Free T3 } \\
\text { (pg/mL) }\end{array}$ & $1.64 \pm 0.16$ & $1.33 \pm 0.22^{\mathrm{a}}$ & $0.93 \pm 0.06^{\mathrm{a}}$ & $<0.3^{a}$ & $<0.3$ & $1.64 \pm 0.24$ & $0.73 \pm 0.09^{b}$ \\
\hline $\begin{array}{l}\text { Free T4 } \\
(\mathrm{ng} / \mathrm{dL})\end{array}$ & $1.80 \pm 0.24$ & $1.21 \pm 0.22^{a}$ & $1.30 \pm 0.23^{a}$ & $2.33 \pm 0.27^{a}$ & $1.99 \pm 0.11^{b}$ & $2.76 \pm 0.24^{a}$ & $1.62 \pm 0.17^{b}$ \\
\hline
\end{tabular}

The results presented in the table are divided according to chemical administered and subdivided according to the presence or absence of 2,4,6-tribromophenol. Ve, vehicle; T3, triiodothyronine; T4, thyroxine; TBP, 2,4,6-tribromophenol. ${ }^{\mathrm{a}} p<0.05$ versus vehicle, ${ }^{\mathrm{b}} p<0.05$ versus without TBP. Data are presented as the mean \pm SD.

\section{Discussion}

Endocrine disturbances occur in various hormone systems, particularly the gonads. Estrogenic compounds are more common and well established as endocrine disruptors [22,23], and evaluation of these compounds has been well documented in the Endocrine Disruptor Screening Program (EDSP) and OECD. However, endocrine disruptors that can interfere with thyroid hormone have not been investigated as thoroughly as estrogenic compounds.

Based on recent study, brominated flame retardants (BFR) was examined for their thyroid function interrupting ability. BFRs was reported to interfere with thyroid function by regulating various thyroid hormone mediated proteins, such as sodium iodide symporter, thyroperoxidase, thyroxine-binding globulin, transthyretin, deiodinase and THR. In this study, TBP, which is regarded as a relatively harmful flame retardant, was assessed for its endocrine disrupting abilities.

Thyroid hormones affect nervous tissue development and maintenance of general tissue functions. For maintaining homeostasis of thyroid hormone system, deiodination is an essential step in thyroid hormone metabolism [12]. There are three subtypes of deiodinase, and their expression and activities are known to be tissue specific. In the pituitary gland, Dio 2 primarily activates $\mathrm{T} 3$ from $\mathrm{T} 4$ by removing one iodide from the outer ring of T4. Dio1 removes both the outer and inner rings of iodine from thyroid hormones. Dios are used as markers of thyroid hormone status or laboratory research. Dios regulate thyroid activity depending on their isoform. TSH is a primary factor for stimulating the thyroid gland. GH is a secreted protein in the pituitary gland that responds to thyroid hormone to increase the metabolism in the body. THR is also regulated by thyroid hormone. In this study, administration of thyroid hormones led to up-regulation of Dio1 transcript in the pituitary to inactivate the thyroid 
hormone. Dio1 transcripts are known as thyroid hormone target genes in pituitary glands [24]. Administration of TBP was found to down-regulate Dio1, and reduction of Dio1 expression inhibited turnover of T4 to T3. Increased Dio1 expression in response to T3 and T4 in the pituitary gland results in activation of T4 to T3. However, the main subtype of the pituitary gland was Dio2, which showed the opposite expression pattern from Dio1 [25], being decreased by T4 treatment and increased by TBP treatment. The down-regulation of Dio1 and up-regulation of Dio2 by TBP suggests that TBP had an anti-thyroid effect on the pituitary gland [26]. Co-treatment with TBP inhibited thyroid hormone T3 and/or T4 action and altered expression of the thyroid hormone-responsive Dio1 and Dio2 genes. Dio1 is a major subtype in the liver that is also induced by T3 and T4 [27]. TBP treatment alone showed no significant effect on Dio1 expression in the liver, while inhibition of T3 and T4 induced up-regulation of Dio1. The subsequent enzyme activity of Dio1 was also highly induced by T3 in rodent liver in a previous study [28].

After identifying the thyroid hormone-disrupting abilities of TBP at the deiodinase transcript level, we examined other thyroid hormone responsive genes in the pituitary gland (Tsh $\beta, T h r \beta 2$ and $G h)$. Increased thyroid hormones are bound to Thr $\beta 2$ and decrease thyroid stimulating hormone (TSH) secretion from the pituitary gland by negative feedback in response to thyroid hormone $[29,30]$. Thus, the decreased level of Thr $\beta 2$ in the present study suggests that TBP acted like an anti-thyroid hormone. While $T \operatorname{sh} \beta$ expression decreased in response to thyroid hormones and increased after TBP treatment, TBP did not inhibit the effects of thyroid hormone when administered together. Interestingly, Gh was induced by TBP, suggesting that TBP could behave like a thyroid hormone.

To synthesize thyroid hormone from follicles, the volume of epithelial cells surrounding the colloid increases. Otherwise, the colloid volume decreases due to uptake of thyroglobulin by epithelial cells. Thus, the activity of the thyroid gland is assumed to be a constant of epithelial volume division colloid volume. These mechanisms are mediated by several proteins expressed in the thyroid gland. Sodium iodide symporter (NIS) plays a major role in storage of iodide in follicular cells. Sodium and iodide ions from blood are taken up by NIS using ATP. Iodination of thyroglobulin (TG) by thyroperoxidase (TPO) is also important to thyroid function [31]. Iodide extruded to colloids is combined with exocytosed TG by TPO [32]. These iodized TG are endocytosed to follicular cells and cleaved to form thyroid hormones. The thyroid gland activity index decreased in response to thyroid hormone and TBP, but was not further decreased by TBP when treated with thyroid hormones.

Thyroid function was analyzed by measuring serum free thyroid hormones because free hormones are more accurately reflected than total hormones [33]. While fT3 was decreased by T3 and TBP, fT4 was decreased by TBP with or without thyroid hormones. Similar to the T3 treated group, serum fT3 was reduced in a dose-dependent manner in response to TBP treatments. T4 treatment does not alter the fT3 levels. Opposite regulation of fT4 was shown in TBP when compared with thyroid hormones. Interestingly, fT3 and fT4 were down regulated after T3 and T4 administration. It is possible that long-term treatment of the hormones caused negative feedback regulation. It was previously reported that T3 and T4 treatment lowered serum TSH levels and induced unsteady levels of the hormone [34]. Other study, also confirmed that BFR mixture reduced the serum T4 level to $73 \%$ of control levels at the highest dose for their experiment (20 mg/kg dosage) [35]. Opposite effect of TBP on the thyroid system was also reported. For example, Norrgran et al., demonstrated that feline hyperthyroidism was induced by brominated phenolic compounds [36]. In summary, we evaluated the thyromimetic effect of TBP in the thyroid gland based on genetic and pathological changes, but the accumulation of TBP in tissues or blood requires further examination.

\section{Conclusions}

In conclusion, TBP regulated TSH followed by serum fT3 and fT4, which again regulated thyroid hormone target genes. These findings suggest that TBP is an endocrine disrupting chemical that acts by interfering with the thyroid hormone system in mice. 
Acknowledgments: This work was supported by the National Research Foundation of Korea (NRF) funded by the Ministry of Education, Science and Technology (grant number: 2015R1A6A1A04020885 and No. 2013-010514). We thank to Ki-Jeong, Na, Chungbuk National University, advices for serum free thyroid hormones measurement and cooperation.

Author Contributions: Dongoh Lee and Eui-Bae Jeung conceived and designed the experiments; Dongoh Lee and Changhwan Ahn performed the experiments; Dongoh Lee and Changhwan Ahn analyzed the data; Eui-Bae Jeung contributed reagents/materials/analysis tools; Dongoh Lee, Eui-Ju Hong and Beum-Soo An wrote the paper. Kyung-Chul Choi and Sang-Hwan Hyun revise the manuscript.

Conflicts of Interest: The authors declare no conflict of interest.

\section{References}

1. Vaitkus, J.A.; Farrar, J.S.; Celi, F.S. Thyroid hormone mediated modulation of energy expenditure. Int. J. Mol. Sci. 2015, 16, 16158-16175. [CrossRef] [PubMed]

2. Schussler, G.C. The thyroxine-binding proteins. Thyroid 2000, 10, 141-149. [CrossRef] [PubMed]

3. Faix, J.D. Principles and pitfalls of free hormone measurements. Best Pract. Res. Clin. Endocrinol. Metab. 2013, 27, 631-645. [CrossRef] [PubMed]

4. Grajower, M.M.; Surks, M.I. Effect of decreased hepatic nuclear l-triiodothyronine receptors on the response of hepatic enzymes to l-triiodothyronine in tumor-bearing rats. Endocrinology 1979, 104, 697-703. [CrossRef] [PubMed]

5. Bassett, J.H.; Harvey, C.B.; Williams, G.R. Mechanisms of thyroid hormone receptor-specific nuclear and extra nuclear actions. Mol. Cell. Endocrinol. 2003, 213, 1-11. [CrossRef] [PubMed]

6. Kurosawa, T.; Hiroi, H.; Tsutsumi, O.; Ishikawa, T.; Osuga, Y.; Fujiwara, T.; Inoue, S.; Muramatsu, M.; Momoeda, M.; Taketani, Y. The activity of bisphenol a depends on both the estrogen receptor subtype and the cell type. Endocr. J. 2002, 49, 465-471. [CrossRef] [PubMed]

7. Jung, E.M.; An, B.S.; Yang, H.; Choi, K.C.; Jeung, E.B. Biomarker genes for detecting estrogenic activity of endocrine disruptors via estrogen receptors. Int. J. Environ. Res. Public Health 2012, 9, 698-711. [CrossRef] [PubMed]

8. Moriyama, K.; Tagami, T.; Akamizu, T.; Usui, T.; Saijo, M.; Kanamoto, N.; Hataya, Y.; Shimatsu, A.; Kuzuya, H.; Nakao, K. Thyroid hormone action is disrupted by bisphenol a as antagonist. J. Clin. Endocrinol. Metab. 2002, 87, 5185-5190. [PubMed]

9. Guo, Y.; Zhou, B. Thyroid endocrine system disruption by pentachlorophenol: An in vitro and in vivo assay. Aquat. Toxicol. 2013, 142-143, 138-145. [CrossRef] [PubMed]

10. Sharan, S.; Nikhil, K.; Roy, P. Disruption of thyroid hormone functions by low dose exposure of tributyltin: An in vitro and in vivo approach. Gen. Comp. Endocrinol. 2014, 206, 155-165. [CrossRef] [PubMed]

11. Zhai, W.; Huang, Z.; Chen, L.; Feng, C.; Li, B.; Li, T. Thyroid endocrine disruption in zebrafish larvae after exposure to mono-(2-ethylhexyl) phthalate (mehp). PLoS ONE 2014, 9, e92465. [CrossRef] [PubMed]

12. Arrojo E Drigo, R.; Fonseca, T.L.; Werneck-de-Castro, J.P.; Bianco, A.C. Role of the type 2 iodothyronine deiodinase (D2) in the control of thyroid hormone signaling. Biochim. Biophys. Acta 2013, 1830, 3956-3964. [CrossRef] [PubMed]

13. Covaci, A.; Harrad, S.; Abdallah, M.A.; Ali, N.; Law, R.J.; Herzke, D.; de Wit, C.A. Novel brominated flame retardants: A review of their analysis, environmental fate and behaviour. Environ. Int. 2011, 37, 532-556. [CrossRef] [PubMed]

14. Watanabe, I.; Sakai, S. Environmental release and behavior of brominated flame retardants. Environ. Int. 2003, 29, 665-682. [CrossRef]

15. Meerts, I.A.; van Zanden, J.J.; Luijks, E.A.; van Leeuwen-Bol, I.; Marsh, G.; Jakobsson, E.; Bergman, A.; Brouwer, A. Potent competitive interactions of some brominated flame retardants and related compounds with human transthyretin in vitro. Toxicol. Sci. 2000, 56, 95-104. [CrossRef] [PubMed]

16. Ezechiáš, M.; Svobodová, K.; Cajthaml, T. Hormonal activities of new brominated flame retardants. Chemosphere 2012, 87, 820-824. [CrossRef] [PubMed]

17. Deng, J.; Liu, C.; Yu, L.; Zhou, B. Chronic exposure to environmental levels of tribromophenol impairs zebrafish reproduction. Toxicol. Appl. Pharmacol. 2010, 243, 87-95. [CrossRef] [PubMed]

18. Legler, J.; Brouwer, A. Are brominated flame retardants endocrine disruptors? Environ. Int. 2003, 29, 879-885. [CrossRef] 
19. Olsen, C.M.; Meussen-Elholm, E.T.; Holme, J.A.; Hongslo, J.K. Brominated phenols: Characterization of estrogen-like activity in the human breast cancer cell-line MCF-7. Toxicol. Lett. 2002, 129, 55-63. [CrossRef]

20. Nair, A.B.; Jacob, S. A simple practice guide for dose conversion between animals and human. J. Basic Clin. Pharm. 2016, 7, 27-31. [CrossRef] [PubMed]

21. Kalisnik, M. A histometric thyroid gland activation index (preliminary report). J. Microsc. 1972, 95, 345-348. [CrossRef] [PubMed]

22. Gray, L.E.; Wilson, V.; Noriega, N.; Lambright, C.; Furr, J.; Stoker, T.E.; Laws, S.C.; Goldman, J.; Cooper, R.L.; Foster, P.M. Use of the laboratory rat as a model in endocrine disruptor screening and testing. ILAR J. 2004, 45, 425-437. [CrossRef] [PubMed]

23. Choi, K.C.; Leung, P.C.; Jeung, E.B. Biology and physiology of calbindin-D9k in female reproductive tissues: Involvement of steroids and endocrine disruptors. Reprod. Biol. Endocrinol. 2005, 3, 66. [CrossRef] [PubMed]

24. Baur, A.; Bauer, K.; Jarry, H.; Köhrle, J. 3,5-diiodo-L-thyronine stimulates type 15 'deiodinase activity in rat Anterior Pituitaries in vivo and in Reaggregate Cultures and GH3 Cells in vitro. Endocrinology 1997, 138, 3242-3248. [CrossRef] [PubMed]

25. Luongo, C.; Martin, C.; Vella, K.; Marsili, A.; Ambrosio, R.; Dentice, M.; Harney, J.W.; Salvatore, D.; Zavacki, A.M.; Larsen, P.R. The selective loss of the type 2 iodothyronine deiodinase in mouse thyrotrophs increases basal TSH but blunts the thyrotropin response to hypothyroidism. Endocrinology 2015, 156, 745-754. [CrossRef] [PubMed]

26. Medina-Gomez, G.; Calvo, R.M.; Obregon, M.J. Thermogenic effect of triiodothyroacetic acid at low doses in rat adipose tissue without adverse side effects in the thyroid axis. Am. J. Physiol. Endocrinol. Metab. 2008, 294, E688-E697. [CrossRef] [PubMed]

27. Maia, A.L.; Goemann, I.M.; Meyer, E.L.; Wajner, S.M. Deiodinases: The balance of thyroid hormone: Type 1 iodothyronine deiodinase in human physiology and disease. J. Endocrinol. 2011, 209, 283-297. [CrossRef] [PubMed]

28. Mullur, R.; Liu, Y.Y.; Brent, G.A. Thyroid hormone regulation of metabolism. Physiol. Rev. 2014, 94, 355-382. [CrossRef] [PubMed]

29. Menezes-Ferreira, M.M.; Petrick, P.A.; Weintraub, B.D. Regulation of thyrotropin (TSH) bioactivity by tsh-releasing hormone and thyroid hormone. Endocrinology 1986, 118, 2125-2130. [CrossRef] [PubMed]

30. De Greef, W.J.; Rondeel, J.M.; van Haasteren, G.A.; Klootwijk, W.; Visser, T.J. Regulation of hypothalamic trh production and release in the rat. Acta Med. Austriaca 1992, 19, 77-79. [PubMed]

31. Taurog, A.; Dorris, M.L.; Doerge, D.R. Mechanism of simultaneous iodination and coupling catalyzed by thyroid peroxidase. Arch. Biochem. Biophys. 1996, 330, 24-32. [CrossRef] [PubMed]

32. Lamas, L.; Taurog, A. The importance of thyroglobulin structure in thyroid peroxidase-catalyzed conversion of diiodotyrosine to thyroxine. Endocrinology 1977, 100, 1129-1136. [CrossRef] [PubMed]

33. Shivaraj, G.; Prakash, B.D.; Sonal, V.; Shruthi, K.; Vinayak, H.; Avinash, M. Thyroid function tests: A review. Eur. Rev. Med. Pharmacol. Sci. 2009, 13, 341-349. [PubMed]

34. Salmela, P.I.; Wide, L.; Juustila, H.; Ruokonen, A. Effects of thyroid hormones (T4,T3), bromocriptine and Triac on inappropriate TSH hypersecretion. Clin. Endocrinol. 1988, 28, 497-507. [CrossRef]

35. Ernest, S.R.; Wade, M.G.; Lalancette, C.; Ma, Y.Q.; Berger, R.G.; Robaire, B.; Hales, B.F. Effects of chronic exposure to an environmentally relevant mixture of brominated flame retardants on the reproductive and thyroid system in adult male rats. Toxicol. Sci. Off. J. Soc. Toxicol. 2012, 127, 496-507. [CrossRef] [PubMed]

36. Norrgran, J.; Jones, B.; Lindquist, N.G.; Bergman, A. Decabromobiphenyl, polybrominated diphenyl ethers, and brominated phenolic compounds in serum of cats diagnosed with the endocrine disease feline hyperthyroidism. Arch. Environ. Contam. Toxicol. 2012, 63, 161-168. [CrossRef] [PubMed]

(C) 2016 by the authors; licensee MDPI, Basel, Switzerland. This article is an open access article distributed under the terms and conditions of the Creative Commons Attribution (CC-BY) license (http://creativecommons.org/licenses/by/4.0/). 